\title{
PENGEMBANGAN MEDIA PEMBELAJARAN DARING MATERI SISTEM PERNAPASAN MANUSIA UNTUK PEBELAJAR SEKOLAH MENENGAH PERTAMA
}

\author{
Erni Nidatul Dwi Utari, Sulton, Eka Pramono Adi \\ Jurusan Teknologi Pendidikan, Fakultas Ilmu Pendidikan, Universitas Negeri Malang \\ Jalan Semarang 5 Malang 65145 0341-574700 \\ Email:ernidwi0501@gmail.com
}

Article History

Received: 05 November 2020, Accepted: 25 Januari 2021, Published: 10 Agustus 2021

\begin{abstract}
Abstrak
Penelitian ini memiliki tujuan mengembangkan produk berupa media pembelajaran daring menggunakan moodle pada materi sistem pernapasan manusia yang layak dan valid digunakan untuk pembelajaran pebelajar kelas VIII SMP. Media pembelajaran daring menggunakan moodle diintegrasikan sebagai media belajar online yang dapat diakses pebelajar melalui web dimanapun dan kapanpun, sehingga dapat menarik motivasi pebelajar untuk belajar secara mandiri. Pada penelitian ini menggunakan model pengembangan Lee dan Owens (2004). Hasil dari validasi ahli media memperoleh persentase nilai sebesar $95 \%$ dan validasi ahli materi memperoleh persentase sebesar nilai $100 \%$. Sedangkan hasil uji kelayakan pebelajar memperoleh persentase sebesar $97,5 \%$. Berdasarkan hasil tersebut media pembelajaran daring menggunakan moodle valid serta layak digunakan pebelajar belajar mandiri. Penggunaan media pembelajaran tersebut menjadi solusi bagi pendidik untuk menyampaikan pembelajaran dengan online agar lebih mudah dan terstuktur serta membantu pebelajar meningkatkan semangat belajar di rumah.
\end{abstract}

Keyword: Pembelajaran Daring; Moodle; Sistem Pernapasan Manusia

\begin{abstract}
This study has the aim of developing a product in the form of online learning media using moodle on the human respiratory system material that is feasible and valid for the learning of VIII grade junior high school students. Online learning media using Moodle is integrated as an online learning medium that can be accessed by students via the web anywhere and anytime, so that it can attract students' motivation to learn independently. This study uses the development model of Lee and Owens (2004). The results of the media expert validation obtained a percentage value of $95 \%$ and the material expert validation obtained a percentage of $100 \%$. While the results of the student feasibility test obtained a percentage of $97.5 \%$. Based on these results, online learning media using moodle is valid and suitable for students to use for independent learning. The use of learning media is a solution for educators to deliver online learning to make it easier and more structured and helps students increase their enthusiasm for learning at home.
\end{abstract}

Keyword: Online Learning; Moodle; Human Respiratory System 


\section{PENDAHULUAN}

Teknologi berkembang pada era modern penting digunakan di semua bidang, salah satunya bidang pendidikan. Teknologi seakan menjadi kebutuhan pokok untuk melangsungkan pembelajaran. Disampaikan oleh (Setyosari, 2016, p.29) pebelajar abad 21, diharuskan mempunyai keterampilan yang dikuasai seperti keterampilan informasi, media serta teknologi. Salah satu penggunaan teknologi untuk sarana penyampaian pembelajaran adalah media. Media disebut suatu alat, sarana, perangkat digunakan sebagai perantara, saluran maupun jembatan komunikasi sebagai penyampaian, penerimaan pesan antara penyampai pesan dan penerima pesan (Sihkabuden, 2011, p.3). Baru - baru ini KBM di sekolah beralih menjadi online dikarenakan pandemi covid 19, sehingga perlu adanya media pembelajaran yang dapat membantu pebelajar belajar mandiri di rumah.

Masa pandemi covid 19 ini mengharuskan sistem pembelajaran diganti dengan pembelajaran daring agar KBM (Kegiatan Belajar Mengajar) tetap berlangsung dengan lancar (Sintema, 2020). Menurut (Engkizar et al., 2018) pembelajaran melalui online atau daring menawarkan waktu serta ruang tidak terbatas bagi pendidik dan pebelajar untuk berkomunikasi maupun belajar. Alat interaksi menggunakan media pembelajaran daring sangat dibutuhkan pebelajar untuk membuat pembelajaran semakin mudah dan lebih efisien serta memungkinkan mereka untuk belajar dimanapun, kapanpun (Abuhassna \& Yahaya, 2018). Konsep pembelajaran daring merupakan pembelajaran elektronik berbasis web atau teknologi informasi dan komunikasi (TIK) dibuat dengan prinsip serta metode tertentu sehingga bisa digunakan sebagai media pembelajaran open source yang menarik (Mu'arif \& Surjono, 2016). Pembelajaran daring dapat memberikan keluasaan kepada pebelajar untuk mengatur waktu belajar (Muhammad Sobri, Nursaptini, 2020). Sehingga perlu adanya media yang membantu KBM melalui daring.

Berdasarkan hasil observasi serta wawancara kepada waka kurikulum SMP Negeri 1 Srengat, didapatkan informasi KBM selama ini belum sepenuhnya dengan maksimal memanfaatkan teknologi untuk pembelajaran. Padahal fasilitas yang tersedia seperti laboratorium komputer serta akses Internet yang cepat sudah tersedia serta sangat memadahi digunakan dalam pembelajaran. Namun, fasilitas tersebut jarang sekali dimanfaatkan karena banyak pendidik masih menggunakan metode ceramah dan penugasan melalui buku LKS (Lembar Kerja Siswa). Ditambah lagi keadaan sekarang mengharuskan pebelajar belajar di rumah, sehingga pendidik mau tidak mau harus mencari cara agar pembelajaran tetap tersampaikan baik meskipun tanpa bertatap muka di kelas. Sedangkan menurut pendidik SMP Negeri 1 Srengat, khususnya pendidik IPA, mereka mengalami kesulitan untuk menyampaikan mata pelajaran Ilmu Pengetahuan Alam (IPA) tanpa media pendukung karena materi yang diajarkan banyak terdapat proses sukar dipahami oleh pebelajar tanpa bantuan media.

Melalui permasalahan tersebut maka diperlukan media pembelajaran daring membantu pendidik menyampaikan materi pembelajaran sehingga pebelajar dapat berpartipasi aktif belajar melalui online. Pembelajaran daring memberikan manfaat untuk membantu menyediakan akses belajar bagi semua orang, sehingga mengatasi hambatan secara fisik sebagai faktor untuk belajar dalam kelas (Crews \& Parker, 2017). Media pembelajaran daring menggunakan LMS (Learning Management System) berupa moodle diharapakan membuat pebelajar menjadi lebih mandiri dan aktif mengamati, melakukan, mendemonstrasikan tidak hanya mendengarkan materi dari pendidik saja. LMS dibangun berdasarkan pengalaman langsung di lapangan menggunakan latar belakang ilmu pendidikan, sehingga LMS mampu mengakomodir hampir semua kebutuhan pendidikan konvensional ditransfer dalam wujud online learning (Irawan \& Surjono, 2018). Materi, bahan ajar dapat divirtualisasikan berbagai format sehingga lebih bervariasi, menarik dan lebih dinamis mampu memotivasi pebelajar untuk lebih jauh dalam KBM (Anggraeni \& Sole, 2018). Pendidik dan pebelajar juga lebih leluasa dalam penggunaan waktu pembelajaran disesuaikan materi pembelajaran IPA telah disesuaikan dengan kebutuhan serta memudahkan untuk saling berinteraksi melalui jaringan Internet (Fayanto et al., 2019). 
Menurut (Turrahma et al., 2018) manfaat bisa didapat melalui belajar melalui online adalah adanya fasilitas untuk e-moderating dimana pengajar melakukan KBM tanpa terkendala oleh jarak, pengajar dan pebelajar dapat menggunakan bahan ajar diakses dengan Internet, pebelajar bisa mempelajari dan me-review bahan pembelajaran melalui online, jika pebelajar memerlukan bahan tambahan untuk belajar maka ia dapat menggunakan Internet, perubahan peran pebelajar dan pengajar menjadi lebih aktif dan pembelajaran relatif lebih efisien dan efektif. Proses penyelenggaraan pembelajaran daring membutuhkan sebuah LMS berfungsi untuk mengatur tata laksana penyelenggaraan pembelajaran difokuskan tidak banyak konten materi, tetapi difokuskan pada pengembangannya dari perspektif kolaborasi serta konstruksi pengetahuan bersama oleh pebelajar (Cabero-Almenara et al., 2019).

Menurut (Aikina \& Bolsunovskaya, 2020) LMS sebagai salah satu manajemen pembelajaran paling efektif untuk mengatasi masalah pembelajaran, pebelajar bebas memilih dan mengakses materi tersedia menggunakan jaringan Internet ramah pengguna dan memenuhi kebutuhan mereka. Menurut (Pradipta \& Wardathi, 2018) pembelajaran daring menggunakan LMS diartikan sebagai konsep pembelajaran memanfaatkan TIK dalam KBM sehingga pembelajaran dilaksanakan secara langsung dapat dilakukan melalui Internet. Belajar secara daring dengan memanfaatkan media atau bantuan alat elektronik meningkatkan efektifitas dan efisiensi dari KBM (Muhammad, R. et al., 2020). Media pembelajaran daring membuat pebelajar menjadi lebih mandiri dan aktif mengamati, melakukan, mendemonstrasikan tidak hanya mendengarkan materi dari pendidik saja. (Yustanti \& Novita, 2019).

Penelitian dilakukan oleh (Akhmadan, 2017), menunjukkan pembelajaran melalui LMS memberikan efek potensial terhadap hasil belajar pebelajar. Sejalan dengan hasil penelitian (Sayekti, 2018) sistem e-learning memberikan media lebih informatif dalam pembelajaran dibandingkan dengan sistem pembelajaran konvensional. Penelitian lain (Febliza \& Okatariani, 2020) LMS digunakan sebagai media pembelajaran valid dan memberikan pengalaman belajar online bagi pebelajar serta pebelajar juga memberikan respon positif pada semua aspek (minat desain, preferensi warna, gambar dan video, kreativitas dan inovasi, komunikasi) dengan rata-rata jumlah persentase dalam kriteria baik. Penelitian selanjutnya dilakukan oleh (Yusuf et al., 2018) menunjukkan hasil ada perbedaan ketrampilan memecahkan masalah antara pembelajaran dibantu dengan LMS dan pembelajaran konvensional. Hal tersebut dibuktikan hasil rata-rata nilai pebelajar mengalami perubahan peningkatan sebelum dan sesudah menggunakan LMS. Sehingga melalui penelitian ini media pembelajaran daring menggunakan LMS dapat dimanfaatkan secara maksimal dan memberikan hasil positif untuk digunakan dalam pembelajaran.

Berdasarkan uraian diatas, dengan adanya media pembelajaran daring menggunakan LMS bertujuan mengetahui pengembangan, kelayakan dan keefektifan media. Selain itu, media pembelajaran dikembangkan ini dapat membuat pebelajar lebih aktif belajar dan menarik perhatian pebelajar agar pembelajaran IPA dapat berjalan dengan optimal. Pendidik dan pebelajar dapat berinteraksi melalui online melalui LMS teroganisir dan sistematis dengan memaksimalkan pemanfaatan fitur ada dalam LMS, seperti forum diskusi sebagai media interaksi antara pendidik dan pebelajar. Penggunaan media pembelajaran daring dengan LMS ini sangat disarankan untuk meningkatkan pemahaman pebelajar saat belajar mandiri di rumah. Media video pembelajaran ditambahkan dalam materi pembelajaran dan memaksimalkan fitur diskusi membuat pebelajar dapat belajar dengan lancar.

\section{METODE}

Penelitian ini menggunakan model penelitian pengembangan William W. Lee dan Diana L. Owens. Model ini cocok digunakan mengembangkan media pembelajaran, hal ini sangat relevan dengan pengembangan media pembelajaran daring menggunakan LMS bertujuan untuk membantu meningkatkan pemahaman serta keaktifan pebelajar dalam PJJ (Pembelajaran Jarak Jauh). Model Lee 
\& Owens memiliki tahap - tahap lengkap, meliputi assessment/analisis terdiri dari dua bagian utama yaitu analisis kebutuhan dan analisis awal-akhir(front-end analysis), desain (design), pengembangan (development), implementasi (implementation) dan evaluasi (evalution) (Lee, W. W. \& Owens, 2004).

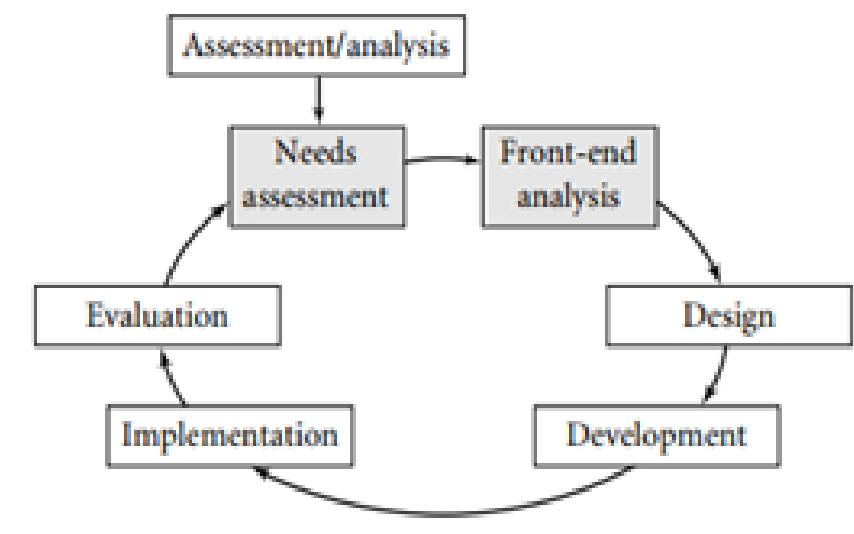

Gambar 1. Model Pengembangan Lee \& Owens (2004)

Kegiatan uji kelayakan dan uji coba produk untuk mengumpulkan atau memperoleh data digunakan untuk menentukan tingkat kevalidan media pembelajaran daring dilakukan satu orang ahli media memiliki keahlian tentang media dan memahami tentang perancangan media pembelajaran serta memiliki pengelaman/profesi berhubungan dengan media pembelajaran serta satu orang ahli materi memiliki pemahaman dan keahlian sesuai dengan materi terdapat dalam media pembelajaran, serta memiliki pengalaman/profesi mengajar materi terdapat dalam media pembelajaran.

Ada beberapa aspek poin dinilai ahli media yaitu aspek desain tampilan yang berupa tata letak/layout tampilan, tulisan, warna, tata letak menu, penempatan judul dan ilustrasi, aspek kemudahan akses berupa pengoperasian, petunjuk penggunaan, menu navigasi, aspek keinteraktifan berupa kekomunikatifan media, kemenarikan,bentuk media, motivasi belajar. Adapun aspek dinilai oleh ahli materi yaitu aspek kelayakan isi yaitu materi terdapat dalam media sesuai dengan kompetensi dasar dan tujuan pembelajaran, aspek kelayakan penyajian seperti sistematika penyajian, contoh-contoh, soal latihan dan sumber relevan, aspek penilaian konstektual yang hubungannya engan motivasi belajar pebelajar. Subyek penelitian dalam pengembangan daring dengan moodle pada mata pelajaran IPA materi sistem pernapasan manusia adalah pebelajar kelas VIII SMP Negeri 1 Srengat dengan uji coba kelompok kecil sebanyak 3 orang. Data yang dikumpulkan menggunakan angket diisi melalui google formulir. Aspek yang dinilai oleh pebelajar desain tampilan, aksebilitas, penyajian materi dan motivasi belajar pebelajar.

Penilaian angket validasi oleh ahli media, ahli materi dan pebelajar menggunakan jenis pengukuran skala likert dengan empat jawaban yaitu SS (Sangat Setuju), S (Setuju), TS (Tidak Setuju) serta STS (Sangat Tidak Setuju). Jenis data diperoleh dari pengembangan elearning menggunakan moodle materi sistem pernapasan manusia adalah data kualitatif dan data kuantitatif. Data kualitatif diperoleh berupa kritik, saran, serta tanggapan tentang media pembelajaran daring dikembangkan dari ahli media, ahli materi dan pebelajar dianalisis menggunakan analisis isi, saran dan tanggapan. Sedangkan data kuantitatif berupa penilaian terhadap media pembelajaran daring dikembangkan dari angket hasil validasi ahli media, ahli materi dan pebelajar serta hasil pre test dan post test. Analisis data kuantitatif menggunakan persentase. Teknik analisis persentase adalah cara untuk mengubah data kuantitatif menjadi bentuk persentase kemudian dijelaskan menggunakan kalimat bersifat kualitatif. Merevisi produk pada tahap terakhir yaitu evaluasi melalui pertimbangan data-data digunakan untuk mengukur kelayakan dan keefektifan media pembelajaran daring yang dikembangkan. Untuk menentukan kriteria kelayakan penggunaan media menurut (Akbar, 2013) dengan kriteria persentase 
$76 \%$ - $100 \%$ dengan kualifikasi sangat valid, persentase 51\%-75\% dengan kualifikasi valid, persentase 26\%-50\% dengan kualifikasi kurang valid dan 0\%-25\% dengan kualifikasi tidak valid.

\section{HASIL}

Dalam implementasi produk media pengembangan daring menggunakan LMS pada mata pelajaran IPA materi sistem pernapasan manusia adalah pebelajar kelas VIII SMP Negeri 1 Srengat diperoleh hasil pada grafik 1 .

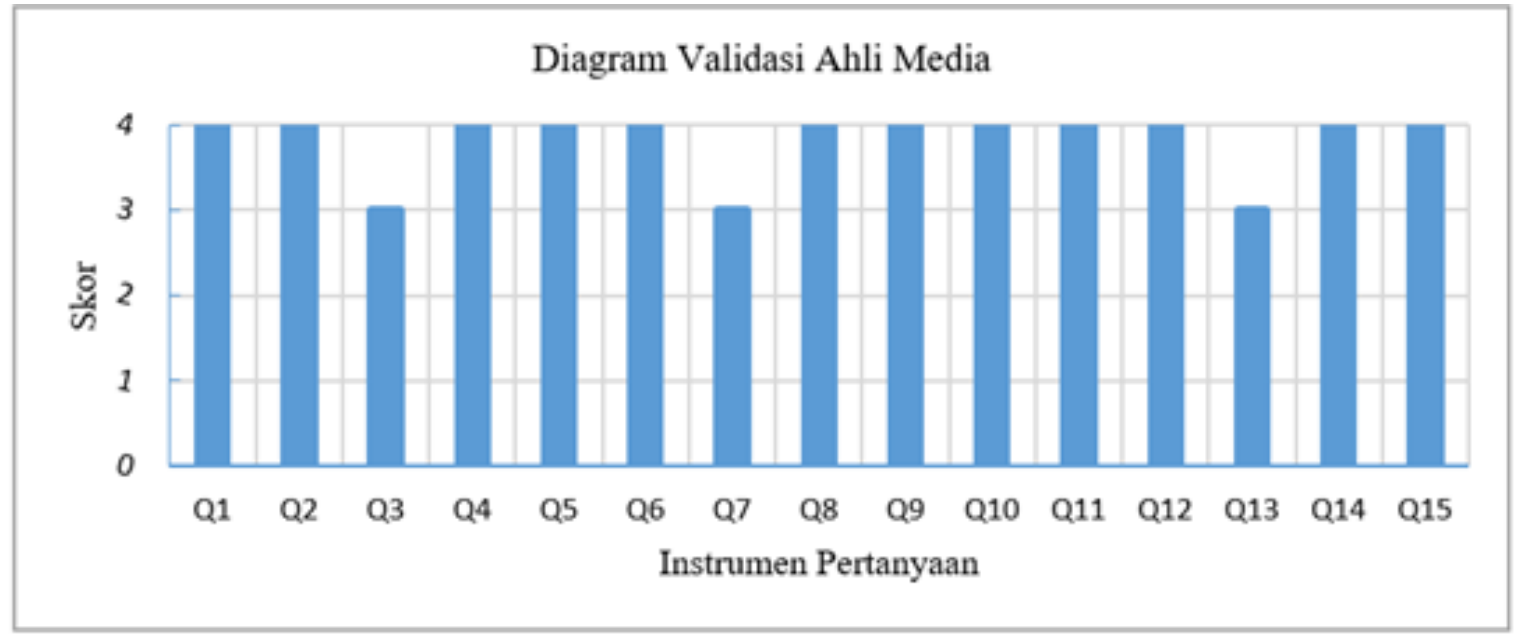

\section{Grafik 1. Tampilan Hasil Data Ahli Media}

Terdapat 15 aspek yang dinilai dalam validasi ahli media untuk pengembangan daring menggunakan moodle materi dipelajaran sistem pernapasan manusia. Hasil validasi ahli media untuk data kuantitatif diperoleh persentase $100 \%$ atau nilai 4 pada 12 aspek dan 3 aspek lainnya memperoleh persentase sebesar 75\% atau nilai 3. Dari keseluruhan aspek dinilai jika diakumulasikan maka hasil ahli media adalah sebesar 3,8 dengan persentase 95\% sehingga dapat diinterprestasikan bahwa media pembelajaran daring menggunakan moodle materi dipelajaran sistem pernapasan manusia memenuhi kriteria valid/layak sesuai tingkat kelayakan media. Selain itu terdapat komentar dan saran dari ahli media yaitu sudah sesuai, hanya saja pengoperasian agak sulit sehingga perlu pendampingan pendidik.

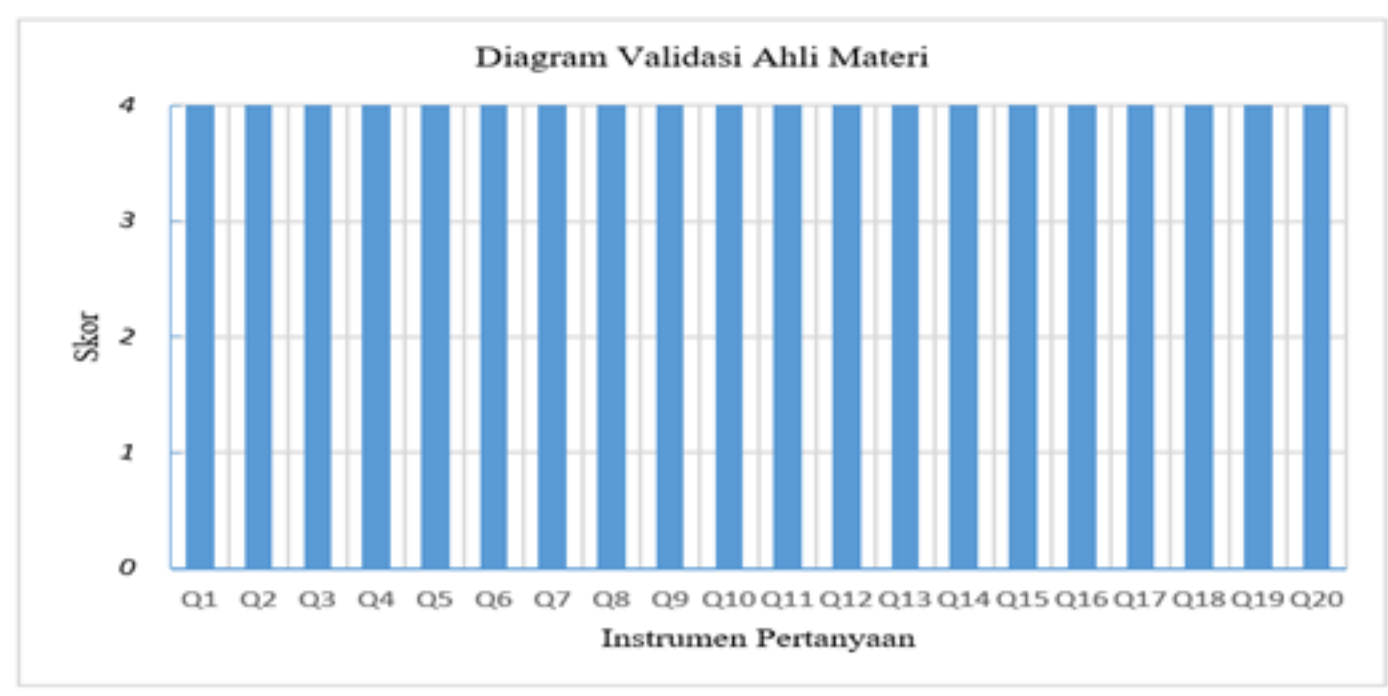

\section{Grafik 2. Tampilan Hasil Data Ahli Materi}

Kemudian, 20 aspek dinilai ahli materi untuk pengembangan media pembelajaran daring dengan moodle pada mata pelajaran IPA materi dipelajaran sistem pernapasan manusia. Hasil validasi ahli media untuk data kuantitatif diperoleh persentase $100 \%$ atau nilai 4 dengan persentase $100 \%$ sehingga 
dapat diinterprestasikan bahwa media pembelajaran daring menggunakan moodle pada mata pelajaran IPA materi dipelajaran sistem pernapasan manusia memenuhi kriteria valid/layak sesuai tingkat kelayakan media. Terdapat komentar dan saran dari ahli materi yaitu penelitian menggunakan media pembelajaran daring perlu disebarluaskan untuk pembelajaran jarak jauh (PJJ).

Berdasarkan pengolahan data, disajikan pada grafik 3 dapat dikaji bahwa dari 3 responden yang menempuh pre test terdapat 1 responden memenuhi kriteria ketuntasan belajar atau memenuhi KKM $(>80)$, sedangkan terdapat 2 responden tidak memenuhi KKM (>80). Tes dilakukan dengan google formulir sebelum responden menggunakan moodle diperoleh rata-rata nilai sebesar 71,6. Selanjutanya untuk post test, ketiga responden mencapai kriteria ketuntasan belajar atau KKM (>80). Tes dilakukan setelah responden menggunakan moodle diperoleh rata-rata nilai 98,3. Sehingga dapat dikatakan terjadi kenaikan nilai sebelum dan sesudah menggunakan e-learning.

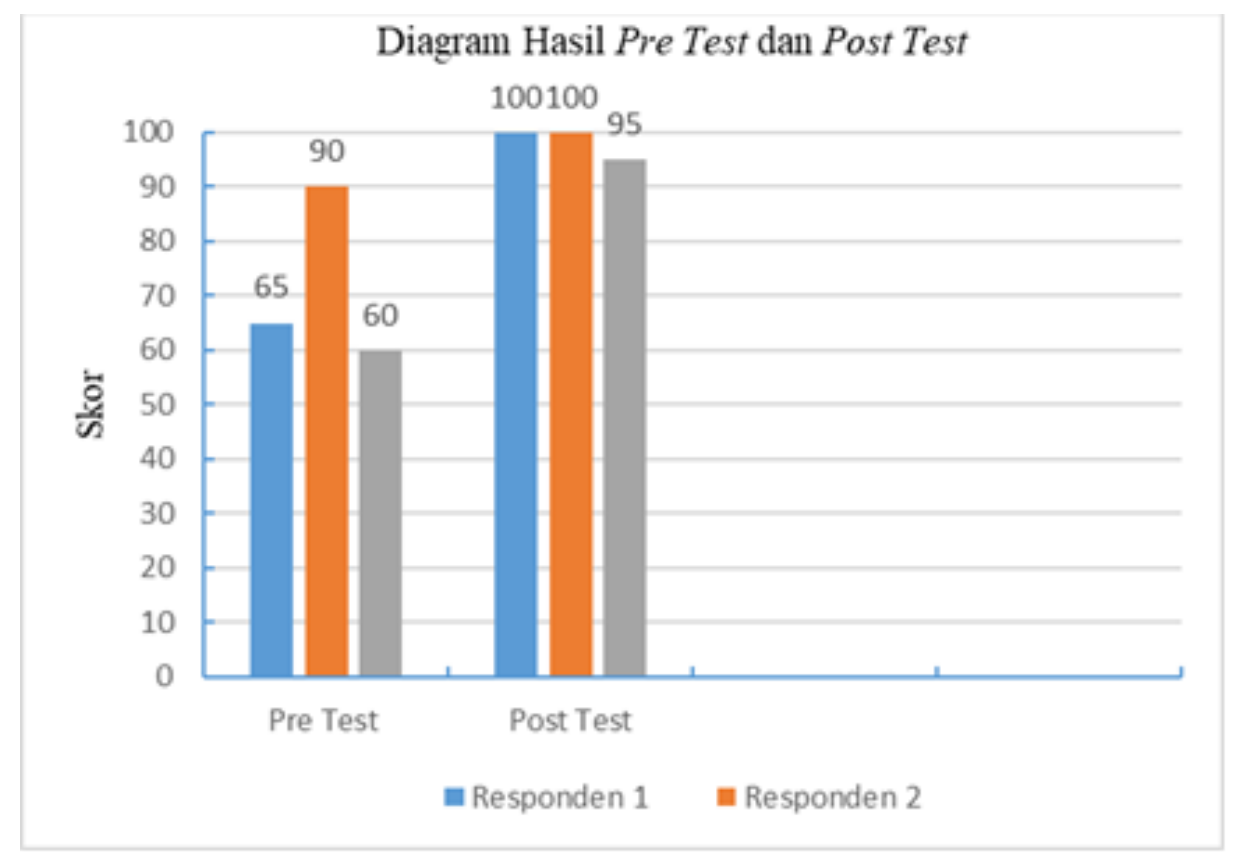

Grafik 3. Tampilan Hasil Uji Pre Test dan Post Test

\section{PEMBAHASAN}

\section{Need Assessment}

Pada saat analisis kebutuhan/need assessment adalah dengan observasi langsung ke sekolah dengan mewawancarai wakil kepala sekolah bagian kurikulum, pendidik mata pelajaran dan pebelajar. Tujuannya agar pengembangan sesuai dengan permasalahan dan kebutuhan yang ada di sekolah. Berdasarkan observasi dilakukan selama pembelajaran melalui daring pendidik hanya memberikan tugas kepada pebelajar. Sedangkan pebelajar hanya mengerjakan tugas lalu dilaporkan kepada pendidik, mereka kesulitan dalam memahami materi karena tidak diberikan penjelasan. Maka media pembelajaran daring menggunakan moodle perlu digunakan pebelajar belajar mandiri di rumah untuk meningkatkan pemahaman materi dipelajaran sistem pernapasan manusia.

\section{Front End Analysis}

Tujuan dari front end analysis adalah mendapatkan informasi lebih detail untuk media yang akan dikembangkan. Tahapan ini menganalisis karakteristik pebelajar serta fasilitas hingga keadaan di SMPN 1 Srengat agar memperoleh gambaran informasi untuk pengembangan yang dilakukan. Pembelajaran daring menggunakan moodle ini cocok digunakan pebelajar untuk belajar mandiri.

\section{Design}


Produk yang dihasilkan berupa media pembelajaran yang dapat dioperasikan melalui laptop, komputer maupun handphone. Media pembelajaran daring yang dikembangkan adalah platform moodle yang dapat diakses pebelajar dimanapun dan kapanmu. LMS ini terdapat video pembelajaran yang membantu pebelajar memahami materi pembelajaran. Terdapat pula kuis untuk mengetahui hasil belajar pebelajar dan digunakan untuk evaluasi pembelajaran.

\section{Development}

Pembelajaran daring ini akan dikemas dalam moodle yang diakses menggunakan website dan jaringan Internet. Moodle digunakan sebagai aplikasi desain e-learning yang memiliki berbagai aktivitas resources dan facilities. Pada pengembangan media pembelajaran daring menggunakan moodle mengambil mata pelajaran IPA materi dipelajaran sistem pernapasan manusia.

\section{Review Ahli Media dan Materi}

Media pembelajaran daring dengan LMS ini telah melalui tahap validasi yang dilakukan oleh ahli materi berjumlah satu orang yaitu pendidik IPA dan satu ahli media dari dosen Teknologi Pendidikan. Hasil validitas pengembangan e-learning menggunakan moodle materi dipelajaran sistem pernapasan manusia ini mendapat respon positif. Persentase data yang diperoleh nilai dari ahli media yaitu sebesar 95\% dengan nilai maksimal 4 dan minimal 3, berdasarkan kriteria yang telah ditetapkan sudah termasuk dalam kriteria valid serta layak digunakan. Persentase data dari ahli media diperoleh nilai sebesar $100 \%$ dengan nilai 4 pada semua aspek sehingga termasuk dalam kriteria valid serta layak digunakan dalam pembelajaran.

Berdasarkan hasil tes pemahaman pebelajar pada kelompok kecil menggunakan pre test dan post test, terjadi kenaikan pencapaian kriteria ketuntasan minimal dari nilai rata-rata pre test sebesar 71,6 menjadi 98,3 pada post test. Berdasarkan hasil tes pemahaman pebelajar pada kelompok kecil menggunakan pre test dan post test, terjadi kenaikan pencapaian kriteria ketuntasan minimal dari nilai rata-rata pre test sebesar 71,6 menjadi 98,3 pada post test. Hal tersebut menunjukkan terjadinya peningkatan nilai sebelum dan sesudah menggunakan daring dengan LMS. Sedangkan respon pebelajar terhadap media pembelajaran daring mendapatkan persentase sebesar 97,5\%. Sehingga pengembangan media pembelajaran daring dengan moodle materi dipelajaran sistem pernapasan manusia ini sudah termasuk dalam kriteria valid serta layak digunakan dalam pembelajaran.

Beberapa penelitian lain seperti yang diungkapkan oleh (Turrahma et al., 2018) pada KBM (Kegiatan Belajar Mengajar) komunikasi terjalin antara Pengajar dan pebelajar melalui pemanfaatan elearning. Informasi yang disajikan melalui e-learning dapat dengan mudah diperoleh pebelajar kapanpun dan dimanapun sehingga didalam mengakses pembelajaran maupun mengerjakan tugas tidak mengalami kendala. Sejalan dengan pendapat (Sayekti, 2018) bahwa sistem e-learning memberikan media yang lebih informatif dalam pembelajaran dibandingkan dengan sistem pembelajaran konvensional. Dengan sistem e-learning, pebelajar dapat mengakses kapanpun mencari informasi mengenai pelajaran mereka agar lebih tepat dalam mengerjakan tugas mereka. E-learning menggunakan moodle ini juga menyediakan referensi dan bahan bagi pebelajar untuk dirujuk sesuai kecepatan pembelajaran mereka sendiri, sehingga itu memungkinkan kebebasan individu dalam memahami materi kursus.

Menurut hasil penelitian (Aikina \& Bolsunovskaya, 2020) faktor kunci yang memotivasi pebelajar untuk belajar menggunakan moodle adalah dapat diakses dengan handphone dan laptop, pebelajar mendapat umpan balik dari pendidik melalui moodle serta materi pembelajaran terorganisir melalui online. Pebelajar umumnya tidak memiliki waktu untuk menelusuri semua jenis materi untuk topik tertentu, sehingga dengan adanya materi yang sudah disesuaikan dalam moodle dapat meningkatkan pengalaman belajar pebelajar (Kolekar et al., 2018). Menurut (Hoerunnisa et al., 2019) media pembelajaran daring dengan platform moodle dapat meningkatkan prestasi dan motivasi pebelajar secara signifikan dan efektif. Selain itu, media pembelajaran daring dengan platform moodle 
dapat meningkatkan partisipasi aktif pebelajar dalam berdiskusi. KBM melalui daring merupakan salah satu inovasi pendidikan untuk menjawab tantangan ketersediaan sumber belajar bermacammacam (Yani F, \& Irfan, 2020). Penggunakan e-learning dengan moodle proses KBM bisa di lakukan melalui online sebagai pelengkap dari sistem belajar yang sudah berjalan dan dapat membantu proses KBM secara maksimal.

Pembelajaran daring membutuhkan rancangan, pelaksanaan dan evaluasi yang memadai. Hal itu bertujuan untuk menjamin proses pembelajara yang bermutu. Hasil penelitian Surahman, dkk (2020), menunjukan bahwa secara umum para pelajaran online di level perguruan tinggi mengaku belum puas dengan kualitas layanan pembelajaran daring khususnya berkaitan dengan kreativitas sajian materi dan umpan balik tugas dari dosen. Untuk mewujukan hal tersebut perlu inovasi dalam pemanfaatkan media yang terindegrasi antara sistem pengelolaan pembelajaran yang dapat diakses melalui smartphone agar lebih ramah pengguna (Surahman, 2019).

Mayoritas hasil pengalaman dari penelitian sebelumnya yaitu media pembelajaran daring menggunakan moodle mendapat hasil positif untuk digunakan dalam pembelajara. Pada penelitian sebelumnya moodle sudah digunakan dalam memfasilitasi belajar pebelajar melalui online namun hanya berfokus pada penyampaian materi pembelajaran saja. Pada penelitian pengembangan ini difokuskan pada bagaimana pendidik dan pebelajar dapat berinteraksi melalui online melalui moodle yang teroganisir dan sistematis dengan baik dan memaksimalkan pemanfaatan fitur yang ada dalam moodle, seperti forum diskusi sebagai media interaksi antara pendidik dan pebelajar. Fasilitas forum diskusi dapat membantu pebelajar saling bertukar informasi antara pebelajar maupun pendidik, tanpa dibatasi ruang dan waktu. Pebelajar dapat mempraktikkan soal dalam kuis yang telah memungkinkan secara mandiri (Sari \& Setiawan, 2018). Penambahan video pembelajaran juga membantu pebelajar dalam memahami materi. Oleh karena itu, media pembelajaran daring melalui moodle keaktifan pebelajar dalam pembelajaran dapat dipantau melalui online oleh pendidik.

\section{SIMPULAN}

Media pembelajaran daring menggunakan moodle materi dipelajaran sistem pernapasan manusia ini merupakan salah satu solusi untuk mengatasi masalah pembelajaran online. Pebelajar dapat secara mudah mengakses e-learning, materi pembelajaran yang terorganisir dalam moodle dapat membantu pebelajar fokus dalam pembahasan materi, pebelajar juga akan secara aktif berpartisipasi dalam berdiskusi, serta partisipasi pebelajar dalam pembelajaran dapat terpantau oleh pendidik. Media pembelajaran daring menggunakan moodle ini sangat mudah digunakan dan dapat diulang-ulang oleh pebelajar untuk belajar mandiri di rumah. Hasil uji kelayakan yang telah dilakukan oleh ahli media memberi hasil positif serta memenuhi kriteria valid atau layak digunakan dalam KBM secara mandiri.

\section{DAFTAR RUJUKAN}

Abuhassna, H., \& Yahaya, N. (2018). Students' utilization of distance learning through an interventional online module based on moore transactional distance theory. Eurasia Journal of Mathematics, Science and Technology Education, 14(7), 3043-3052. https://doi.org/10.29333/ejmste/91606

Aikina, T. Y., \& Bolsunovskaya, L. M. (2020). Moodle-based learning: Motivating and demotivating factors. International Journal of Emerging Technologies in Learning, 15(2), 239-248. https://doi.org/10.3991/ijet.v15i02.11297

Akhmadan, W. (2017). Pengembangan Bahan Ajar Materi Garis dan Sudut Menggunakan Macromedia Flash dan Moodle Kelas VII Sekolah Menengah Pertama. Jurnal Gantang, 2(1), 27-40. https://doi.org/10.31629/jg.v2i1.62

Anggraeni, D. M., \& Sole, F. B. (2018). E-Learning Moodle, Media Pembelajaran Fisika Abad 21. Jurnal Penelitian Dan Pengkajian Ilmu Pendidikan: E-Saintika, 1(2), 57. https://doi.org/10.36312/e-saintika.v1i2.101 
Cabero-Almenara, J., Arancibia, M. L., \& Del Prete, A. (2019). Technical and didactic knowledge of the moodle LMS in higher education. Beyond functional use. Journal of New Approaches in Educational Research, 8(1), 25-33. https://doi.org/10.7821/naer.2019.1.327

Crews, J., \& Parker, J. (2017). The Cambodian experience: exploring university students' perspectives for online learning. Issues in Educational Research, 27(4), 697-719.

Engkizar, E., Muliati, I., Rahman, R., \& ... (2018). The Importance of Integrating ICT into Islamic Study Teaching and Learning Process. Khalifa Journal of Islamic ..., 1(2), 148-168. http://kjie.ppj.unp.ac.id/index.php/kjie/article/view/9

Fayanto, S.-, Kawuri, M. Y. R. T., Jufriansyah, A., Setiamukti, D. D., \& Sulisworo, D. (2019). Implementation E-Learning Based Moodle on Physics Learning in Senior High School. Indonesian Journal of Science and Education, 3(2), 93. https://doi.org/10.31002/ijose.v3i2.1178

Febliza, A., \& Okatariani, O. (2020). The Development of Online Learning Media by Using Moodle for General Chemistry Subject. Journal of Educational Science and Technology (EST), 6(1), 40. https://doi.org/10.26858/est.v6i1.12339

Hoerunnisa, A., Suryani, N., \& Efendi, A. (2019). The Effectiveness of the Use of E-Learning in Multimedia Classes To Improve Vocational Students' Learning Achievement and Motivation. Kwangsan: Jurnal Teknologi Pendidikan, 7(2), 123. https://doi.org/10.31800/jtp.kw.v7n2.p123-137

Irawan, R., \& Surjono, H. D. (2018). Pengembangan e-learning berbasis moodle dalam peningkatkan pemahaman lagu pada pembelajaran bahasa inggris. Jurnal Inovasi Teknologi Pendidikan, 5(1), 1-11. https://doi.org/10.21831/jitp.v5i1.10599

Kolekar, S. V., Pai, R. M., \& Manohara Pai, M. M. (2018). Adaptive User Interface for Moodle based E-learning System using Learning Styles. Procedia Computer Science, 135, 606-615. https://doi.org/10.1016/j.procs.2018.08.226

Lee, W. W. \& Owens, D. L. (2004). Multimedia-Based Instructional Design, (2nd Ed). San Francisco : Pfeiffer.

Mu'arif, H. A., \& Surjono, H. D. (2016). Pengembangan E-Learning Berbasis Pendekatan Ilmiah Pada Mata Pelajaran IPA di SMP Negeri 5 Yogyakarta. Jurnal Inovasi Teknologi Pendidikan, 3(2), 195. https://doi.org/10.21831/jitp.v3i2.11143

Muhammad, H., R. Eka Murtinugraha, \& Sittati Musalamah. (2020). Pengembangan Media Pembelajaran E-Learning Berbasis Moodle Pada Mata Kuliah Metodologi Penelitian. Jurnal PenSil, 9(1), 54-60. https://doi.org/10.21009/jpensil.v9i1.13453

Muhammad Sobri, Nursaptini, S. N. (2020). Mewujudkan kemandirian belajar melalui pembelajaran berbasis daring diperpendidikan tinggi pada era industri 4.0. Jurnal Pendidikan Glasser, 4, 6471.

Pradipta, A. W., \& Wardathi, A. N. (2018). E-Learning Development Based On Moodle V.3.1. To Improve Concept Understanding Of Learning And Teaching Course. 419-427.

Sari, P. A., \& Setiawan, A. (2018). The Development of Internet-Based Economic Learning Media using Moodle Approach. International Journal of Active Learning, 3(2), 100-109. http://journal.unnes.ac.id/nju/index.php/ijal

Sayekti, R. (2018). The Implementation of E-learning System at UIN Sumatera Utara in Response to Technology Challenge in Education. Journal of Physics: Conference Series, 970(1). https://doi.org/10.1088/1742-6596/970/1/012026

Setyosari. (2016). Metode Penelitian Pendidikan dan Pengembangan. Jakarta :Prenada Media.

Sihkabuden. (2011). Media Pembelajaran. Malang: Departemen Pendidikan Nasional Universitas Negeri Malang Fakultas Ilmu Pendidikan. 
Sintema, E. J. (2020). Effect of COVID-19 on the performance of grade 12 students: Implications for STEM education. Eurasia Journal of Mathematics, Science and Technology Education, 16(7). https://doi.org/10.29333/EJMSTE/7893

Surahman, E. (2020, October). Student Satisfaction toward Quality of Online Learning in Indonesian Higher Education During the Covid-19 Pandemic. In 2020 6th International Conference on Education and Technology (ICET) (pp. 120-125). IEEE.

Surahman, E. (2019). Integrated mobile learning system (imoles) sebagai upaya mewujudkan masyarakat pebelajar unggul era digital. JINOTEP (Jurnal Inovasi Dan Teknologi Pembelajaran) Kajian Dan Riset Dalam Teknologi Pembelajaran, 5(2), 50-56.

Turrahma, A., Satyariza, E. N., \& Ibrahim, A. (2018). Pemanfaatan E-Learning Berbasis Lcms Moodle Dalam Peningkatan Efisiensi Dan Efektivitas Serta Kualitas Media Pembelajaran Pebelajar Di Man Sakatiga. Jurnal Nasional Pendidikan Teknik Informatika (JANAPATI), 6(3), 327. https://doi.org/10.23887/janapati.v6i3.12672

Yani Fitriyani, Irfan Fauzi, M. Z. S. (2020). Jurnal Kependidikan: Jurnal Hasil Penelitian Dan Kajian Kepustakaan, 6(2), 165-175.

Yustanti, I., \& Novita, D. (2019). Pemanfaatan E-Learning Bagi Para Pendidik Di Era Digital 4.0. Jurnal Sosial Humaniora Sigli, 2(2), 35-41. https://doi.org/10.47647/jsh.v2i2.169

Yusuf, T. M., Wartono, \& Koeshandayanto, S. (2018). ICT Literacy and Problem Solving Skill of Senior High School. 6(3), 88-93. 